Asia Pacific Journals

\title{
APPLICATION OF PUGH SELECTION MATRIX AND TOPSIS METHOD FOR FUEL LEVEL SENSING TECHNOLOGY SELECTION
}

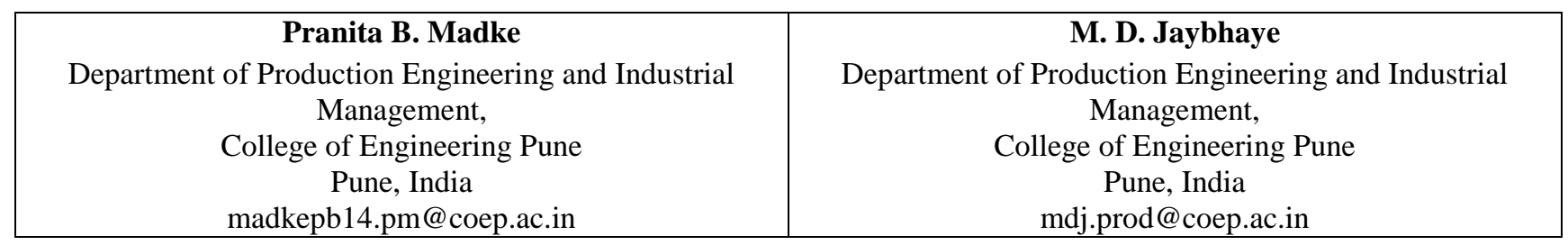

\section{Abstract}

Technology selection is one of the most important steps in Design Process. Choosing the right technology alternative, there is not always a single definite criterion of selection, and decision makers have to take into account a large number of criteria including technological, economic, ethical, political, legal, and social factors. The proper technology selection for Fuel Level Sensor using Pugh Selection Matrix and TOPSIS Method for its application in Heavy Commercial Vehicles is discussed in this paper. In this paper, factors affecting sensor technology selection are identified. Various level sensing technologies are compared across these criteria using Pugh Selection Matrix and TOPSIS Method. The entire procedure is illustrated and finally the best technology is selected for fuel level sensing for Heavy Commercial Vehicles.

Keywords-Fuel Level sensor, Pugh Selection Matrix, Heavy Commercial Vehicles, TOPSIS, Criteria

\section{INTRODUCTION}

Fuel level sensor is a device to indicate the level of the fuel in fuel tank fitted in an automobile. This will have features to communicate the fuel level to the dashboard of the vehicle and is of significant attention to the driver during vehicle usage. Heavy Commercial vehicles have a very particular requirement when it comes to fuel tanks configuration, depending on usage, road conditions, weight distribution and application. After the selection of the fuel tank layout, the challenge is to correctly select the level sensor system, which provides useful information to the vehicle driver. If this measurement is not correctly performed, a significant logistic issue is raised, as usually, a commercial vehicle with full load carries up to 400-600 liters of diesel. Even though the selection of the sensor technology is sometimes neglected during the product development, in this particular case its wrong choice can lead to errors and, as mentioned before, logistics issues. The objective of any selection procedure is to identify appropriate selection criteria, and obtain the most appropriate combination of criteria in conjunction with the real requirement. Thus, efforts need to be extended to identify those criteria that influence an alternative selection for a given problem, using simple and logical methods, to eliminate unsuitable alternatives, and to select the most appropriate alternative to strengthen existing selection procedures.

\section{TECHNOLOGY}

\section{A. TFR (Thick Film Resistor)}

Presently, the float arm type with Thick Film Resistor (TFR) fuel level sensors are being used. Most current automotive and light truck fuel level sensors are essentially Thick Film Resistor (TFR) that have been designed to survive the chemically harsh environments found in the fuel tank [7]. These sensors are often designed with a float arm pinned to the center of a rotary potentiometer consisting of resistors track created by thick film resistive ink technology. This design concept offers the potential for both long life and low cost. The float arm is mounted vertically, and liquid level changes produce a rotary motion for the potentiometer contacts. This change of position alters the resistive value of the sensor.

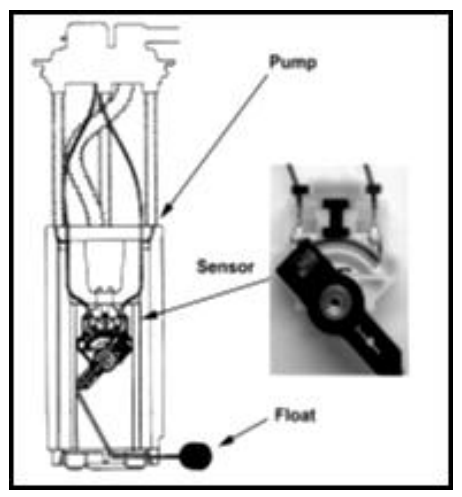

Fig1. TFR Fuel Level Sensor

\section{B. Other Level Sensing Technologies}

The alternative level sensing technology options have been identified and studied thoroughly. These technologies are as follows: RF Capacitance, RADAR, Ultrasonic/Sonic, Magnetostrictive, Anisotropic Magneto resistive, Hall Effect and LVDT.

\section{METHODOLOGY}

\section{A. Pugh Process}

A Pugh Matrix can be used whenever there is the need to decide amongst a number of alternatives. Although specifically developed by Stuart Pugh to help in selecting between a numbers of design alternatives, the tools has in recent years be used a general purpose decision making aid because of its ease of use. The Pugh Matrix is easy to use and relies upon a series of pairwise comparisons between design 


\section{Asia Pacific Journals}

candidates against a number of criteria or requirements. One of its key advantages over other decision-making tools such as the Decision Matrix is its ability to handle a large number of decision criteria. [9]

Step 1: Criteria for selection are identified and clearly defined. The robustness and validity of the outcome is fundamentally dependent on an appropriate set of criteria/requirements. Rushing this step usually results in a non-robust outcome that is challenged and overturned. The following criteria were identified and are given in Table I.

Table I Selection Criteria

\begin{tabular}{l}
\hline Criteria \\
\hline Effect of Operating Temperature Range \\
Effect of Fuel slosh \\
Effect of Presence of Impurity in Fuel \\
Mechanical Shock and Vibration \\
Cost \\
Accuracy \\
Suitability for automobile \\
Resolution \\
Linearity
\end{tabular}

Step 2: Thick Film Resistor (TFR) based sensor design option is the baseline and core all criteria/requirements as ' 0 ' for this baseline. As TFR sensor is the existing design its performance is reasonably well known.

Step 3: Each candidate design option is compared against the baseline design, criteria by criteria and a pair-wise score is decided with: $0=$ same, $1=$ better, $-1=$ worse. The Pugh Selection Matrix is shown in Table II.

Pugh Matrix for sensor technology selection is shown below with all the weightage values and respective calculations.

Step 4: Assign Weightages to the criteria. Typically the weightage is on a 1 to 10 scale with 1 the lowest and 10 the highest weighting.

Step 5: For each candidate design option the total score can be calculated by summing the number of +1 and -1 . The highest ranked score is the "winner" but use common sense DON'T just select "highest" ranked concept.

TABLE II. PUGH SELECTION MATRIX

\begin{tabular}{|c|c|c|c|c|c|c|c|c|c|c|}
\hline \multirow[b]{2}{*}{ Criteria } & \multirow[b]{2}{*}{ 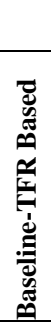 } & \multirow[b]{2}{*}{ 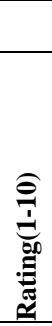 } & \multicolumn{8}{|c|}{ Alternatives } \\
\hline & & & 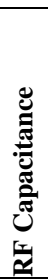 & 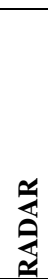 & 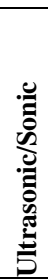 & 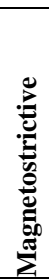 & 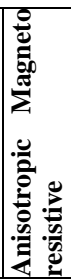 & 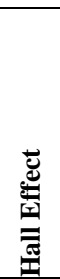 & 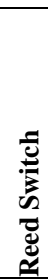 & 实 \\
\hline $\begin{array}{l}\text { Operating } \\
\text { Temperature }\end{array}$ & 0 & 7 & 1 & 1 & -1 & 1 & 1 & 1 & 1 & 1 \\
\hline Fuel slosh & 0 & 6 & 1 & -1 & -1 & -1 & 0 & 1 & 0 & 1 \\
\hline $\begin{array}{l}\text { Presence of } \\
\text { Impurity }\end{array}$ & 0 & 7 & -1 & 1 & -1 & 1 & 0 & -1 & 0 & 1 \\
\hline
\end{tabular}

\begin{tabular}{|l|l|l|l|l|l|l|l|l|l|l|}
\hline $\begin{array}{l}\text { Mechanical } \\
\text { Shock and } \\
\text { Vibration }\end{array}$ & 0 & 6 & 1 & 1 & 1 & -1 & 0 & 0 & 0 & 1 \\
\hline Cost & 0 & 10 & -1 & -1 & -1 & -1 & -1 & -1 & 0 & -1 \\
\hline Accuracy & 0 & 9 & 1 & 1 & 1 & 1 & 0 & 1 & 0 & 1 \\
\hline $\begin{array}{l}\text { Suitable for } \\
\text { automobile }\end{array}$ & 0 & 8 & 1 & 1 & 1 & -1 & 0 & 1 & 0 & 0 \\
\hline Resolution & 0 & 10 & 1 & 1 & 1 & 1 & 0 & 1 & 0 & 1 \\
\hline Linearity & 0 & 7 & 1 & 0 & 0 & 0 & 0 & 0 & 0 & 0 \\
\hline
\end{tabular}

\begin{tabular}{|l|l|l|l|l|l|l|l|l|l|l|}
\hline $\begin{array}{l}\text { Sum of } \\
\text { Positives }\end{array}$ & & & 7 & 6 & 4 & 4 & 1 & 5 & 1 & 6 \\
\hline $\begin{array}{l}\text { Sum of } \\
\text { Negatives }\end{array}$ & & & 2 & 2 & 4 & 4 & 1 & 2 & 0 & 1 \\
\hline Sum of Same & & & 0 & 1 & 1 & 1 & 7 & 2 & 8 & 2 \\
\hline $\begin{array}{l}\text { Weighted } \\
\text { Sum of } \\
\text { Positives }\end{array}$ & & & 53 & 47 & 33 & 33 & 7 & 40 & 7 & 45 \\
\hline $\begin{array}{l}\text { Weighted } \\
\text { Sum of } \\
\text { Negatives }\end{array}$ & & & 17 & 16 & 30 & 30 & 10 & 17 & 0 & 10 \\
\hline Total & & & 36 & 31 & 3 & 3 & -3 & 23 & 7 & 35 \\
\hline
\end{tabular}

\section{B. TOPSIS and AHP Method}

The Analytic Hierarchy Process is a procedure designed to quantify managerial judgments of the relative importance of each of several conflicting criteria used in the decision making process. TOPSIS (Technique for Order of Preference by Similarity to Ideal Solution) method was introduced for the first time by Yoon and Hwang and was appraised by surveyors and different operators. TOPSIS is a decision making technique. It is a goal based approach for finding the alternative that is closest to the ideal solution. In this method, alternative technologies are graded based on ideal solution similarity. If an alternative is more similar to an ideal solution, it has a higher grade. Ideal solution is a solution that is the best from any aspect that does not exist practically and we try to approximate it. Basically, for measuring similarity of an alternative to ideal level and non-ideal, we consider distance of that design from ideal and non-ideal solution. In this paper, we have used AHP to help us measure the relative importance or the weighted values of several criteria identified for Fuel level Sensor selection. These weightages are further used in TOPSIS Method. Steps carried out in AHP process are given below.

Step 1- List the overall selection criteria is identified. Selection criteria are categorized as beneficial and nonbeneficial.

Step 2- A pairwise comparison matrix of Selection criteria is developed based on the scale given in Table III. This is a $\mathrm{m} *$ $\mathrm{m}$ real matrix, where $\mathrm{m}$ is the number of evaluation criteria considered. The diagonal elements of the matrix are 1. Each entry $a_{j k}$ of the matrix represents the importance of the $j_{\text {th }}$ criterion relative to the $\mathrm{k}_{\mathrm{th}}$ criterion. The Matrix is given in Table IV. 


\section{Asia Pacific Journals}

TABLE III. TABLE OF RELATIVE SCORES

\begin{tabular}{|c|l|}
\hline Value of $\mathbf{a}_{\mathbf{j k}}$ & Interpretation \\
\hline 1 & $\mathrm{j}$ and $\mathrm{k}$ are equally important \\
\hline 3 & $\mathrm{j}$ is slightly more important than $\mathrm{k}$ \\
\hline 5 & $\mathrm{j}$ is more important than $\mathrm{k}$ \\
\hline 7 & $\mathrm{j}$ is strongly more important than $\mathrm{k}$ \\
\hline 9 & $\begin{array}{l}\mathrm{j} \text { is absolutely more important than } \\
\mathrm{k}\end{array}$ \\
\hline & $* 2,4,6,8=$ Intermediate Values \\
\hline
\end{tabular}

Step 3- The principal eigenvalue and the corresponding normalized right eigenvector of the comparison matrix give the relative importance of the various criteria being compared. The elements of the normalized eigenvector are termed weights with respect to the criteria and ratings with respect to the alternatives.

Table IV AHP Matrix

\begin{tabular}{|c|c|c|c|c|c|c|c|c|c|}
\hline $\begin{array}{l}\text { Criteria- } \\
\text { Matrix(A) }\end{array}$ & 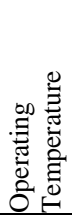 & 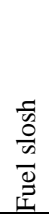 & 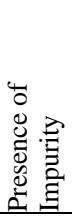 & 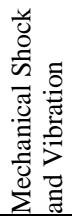 & 范 & 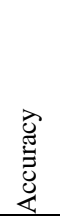 & 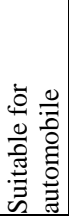 & 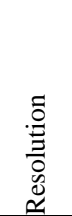 & 䔍 \\
\hline $\begin{array}{l}\text { Operating } \\
\text { Temperature }\end{array}$ & 1 & 2 & 1 & 2 & 1 & 1 & 1 & 1 & 1 \\
\hline Fuel slosh & 0.5 & 1 & 0.5 & 1 & 1 & 1 & 1 & 1 & 1 \\
\hline $\begin{array}{l}\text { Presence of } \\
\text { Impurity }\end{array}$ & 1 & 2 & 1 & 3 & 1 & 1 & 1 & 1 & 1 \\
\hline $\begin{array}{l}\text { Mechanical } \\
\text { Shock and } \\
\text { Vibration }\end{array}$ & 0.5 & 1 & 0.33 & 1 & 1 & 1 & 1 & 1 & 1 \\
\hline Cost & 1 & 1 & 1 & 1 & 1 & 2 & 7 & 1 & 5 \\
\hline Accuracy & 1 & 1 & 1 & 1 & 0.5 & 1 & 2 & 0.5 & 2 \\
\hline $\begin{array}{l}\text { Suitable for } \\
\text { automobile }\end{array}$ & 1 & 1 & 1 & 1 & 0.14 & 0.5 & 1 & 0.33 & 2 \\
\hline Resolution & 1 & 1 & 1 & 1 & 1 & 2 & 3 & 1 & 4 \\
\hline Linearity & 1 & 1 & 1 & 1 & 0.2 & 0.5 & 0.5 & 0.25 & 1 \\
\hline
\end{tabular}

Step 4- The consistency of the matrix of order $\mathrm{m}$ is evaluated. Comparisons made by this method are subjective and the AHP tolerates inconsistency through the amount of redundancy in the approach. If this consistency index fails to reach a required level then answers to comparisons may be re-examined. The consistency index, $\mathrm{CI}$, is calculated as,

$$
C I=\left(\lambda_{\max }-m\right) /(m-1)
$$

Where, $\lambda_{\max }$ is the maximum eigenvalue of the judgement matrix. This CI can be compared with that of a random matrix, RI. The ratio derived, CI/RI, is termed the consistency ratio, CR. CR should be less than 0.1 .

Step 5- If CR is less than 0.1 than the elements of the normalized eigenvector are finalized as the weights of the criteria.

Thus by following the steps given consistent weightages are calculated and given in Table V.
TABLE V. WEIGHTAGES

\begin{tabular}{|l|l|}
\hline Criteria & Weightages \\
\hline Operating Temperature & 0.1239 \\
\hline Fuel slosh & 0.0911 \\
\hline Presence of Impurity & 0.1296 \\
\hline Mechanical Shock and Vibration & 0.0869 \\
\hline Cost & 0.1703 \\
\hline Accuracy & 0.1062 \\
\hline Suitable for automobile & 0.0755 \\
\hline Resolution & 0.1512 \\
\hline Linearity & 0.0653 \\
\hline
\end{tabular}

General TOPSIS process with 7 steps is listed below: [6] Step 1- Form a decision matrix. The structure of the matrix can be expressed as follows:

$$
D=\left[\begin{array}{ccccccc} 
& X_{1} & X_{2} & \cdots & X_{j} & \cdots & X_{m} \\
A_{1} & x_{11} & x_{12} & \cdots & x_{1 j} & \cdots & x_{1 m} \\
A_{2} & x_{21} & x_{22} & \cdots & x_{2 j} & \cdots & x_{2 m} \\
\vdots & \vdots & \vdots & \cdots & \vdots & \vdots & \vdots \\
A_{i} & x_{i 1} & x_{i 2} & \cdots & x_{i j} & \cdots & x_{i m} \\
\vdots & \vdots & \vdots & \cdots & \vdots & \vdots & \vdots \\
A_{n} & x_{n 1} & x_{n 2} & \cdots & x_{n j} & \cdots & x_{n m}
\end{array}\right]
$$

Where

$\mathrm{Ai}=\mathrm{i}_{\text {th }}$ alternative technology

$X_{i j}=$ the numerical outcome of the $i_{t h}$ alternative technology with respect to $j_{\text {th }}$ criteria

So the Matrix developed is shown in Table VI based on scale given in Table VII.

Step 2-Normalize the decision matrix D by using the following formula:

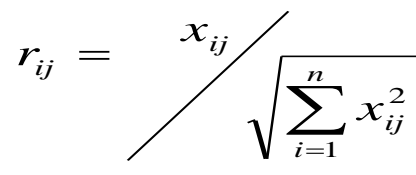

Step 3-Construct the weighted normalized decision matrix by multiplying the normalized decision matrix by its associated weights calculated by. The weighted normalized value $\mathrm{v}_{\mathrm{ij}}$ is calculated as:

$$
\mathrm{v}_{\mathrm{ij}}=w_{i j} * r_{i j}
$$

\begin{tabular}{|c|c|c|c|c|c|c|c|c|c|}
\hline Matrix D & 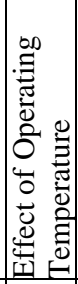 & 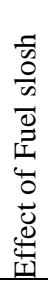 & 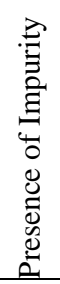 & 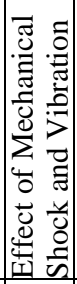 & $\overrightarrow{0}$ & 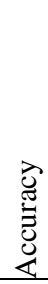 & 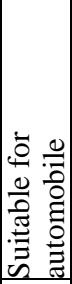 & 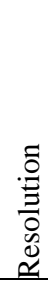 & 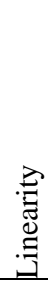 \\
\hline TFR & 5 & 9 & 5 & 7 & 5 & 5 & 9 & 5 & 5 \\
\hline RF Capacitance & 5 & 5 & 5 & 5 & 7 & 7 & 9 & 9 & 9 \\
\hline RADAR & 5 & 7 & 7 & 5 & 7 & 7 & 7 & 9 & 7 \\
\hline
\end{tabular}

TABLE VI. DECISION MATRIX 
Asia Pacific Journals

\begin{tabular}{|l|l|l|l|l|l|l|l|l|l|}
\hline Ultrasonic/Sonic & 5 & 7 & 7 & 5 & 7 & 7 & 7 & 9 & 7 \\
\hline Magnetostrictive & 5 & 7 & 5 & 5 & 7 & 7 & 5 & 5 & 5 \\
\hline $\begin{array}{l}\text { Anisotropic } \\
\text { Magneto resistive }\end{array}$ & 5 & 7 & 5 & 7 & 7 & 5 & 7 & 5 & 5 \\
\hline Hall Effect & 5 & 5 & 7 & 5 & 9 & 9 & 7 & 7 & 5 \\
\hline Reed Switch & 5 & 7 & 5 & 7 & 5 & 5 & 7 & 5 & 5 \\
\hline LVDT & 7 & 7 & 5 & 5 & 5 & 7 & 7 & 7 & 5 \\
\hline
\end{tabular}

TABLE VII. TOPSIS SCALE

\begin{tabular}{|l|l|l|l|}
\hline CRITERIA & 5 & 7 & 9 \\
\hline $\begin{array}{l}\text { Effect of Operating } \\
\text { Temperature }\end{array}$ & Low & High & Very High \\
\hline Effect of Fuel slosh & Low & High & Very High \\
\hline Presence of Impurity & Low & High & Very High \\
\hline $\begin{array}{l}\text { Effect of Mechanical } \\
\text { Shock and Vibration }\end{array}$ & Low & High & Very High \\
\hline Cost & Low & High & Very High \\
\hline Accuracy & High & Very High & $\begin{array}{l}\text { Extremely } \\
\text { High }\end{array}$ \\
\hline $\begin{array}{l}\text { Suitability for } \\
\text { automobile }\end{array}$ & High & Very High & $\begin{array}{l}\text { Extremely } \\
\text { High }\end{array}$ \\
\hline Resolution & High & Very High & $\begin{array}{l}\text { Extremely } \\
\text { High }\end{array}$ \\
\hline Linearity & High & Very High & $\begin{array}{l}\text { Extremely } \\
\text { High }\end{array}$ \\
\hline
\end{tabular}

Step 4- Determine the positive ideal solution and negative ideal solution.

$$
\begin{aligned}
A^{*} & =\left\{\left(\max v_{i j} \mid j \in J\right),\left(\min v_{i j} \mid j \in \hat{J}\right)\right\} \\
A^{-} & =\left\{\left(\min v_{i j} \mid j \in J\right),\left(\max v_{i j} \mid j \in \hat{J}\right)\right\}
\end{aligned}
$$

$\mathbf{J}=1,2,3 \ldots \mathrm{n}$ where $\mathbf{J}$ is associated with the beneficial criteria

$\hat{\mathrm{J}}=1,2,3 \ldots \mathrm{n}$ where $\hat{\mathrm{J}}$ is associated with the non-beneficial criteria where,

TABLE VIII. CLASSIFICATION OF CRITERIA

\begin{tabular}{|l|l|}
\hline Non-Beneficial & Beneficial \\
\hline $\begin{array}{l}\text { Effect of Operating } \\
\text { Temperature }\end{array}$ & Accuracy \\
\hline Effect of Fuel slosh & $\begin{array}{l}\text { Suitability for } \\
\text { automobile }\end{array}$ \\
\hline Presence of Impurity & Resolution \\
\hline $\begin{array}{l}\text { Effect of Mechanical } \\
\text { Shock and Vibration }\end{array}$ & Linearity \\
\hline Cost & \\
\hline
\end{tabular}

Step 5-

Calculate the separation measure. The separation of each alternative from the positive ideal one is given by:

$$
S^{*}=\sqrt{\sum_{j=1}^{n}\left(v_{i j}-v_{j}^{*}\right)^{2}}
$$

where $\mathrm{i}=1,2, \ldots, \mathrm{m}$

Similarly, the separation of each alternative from the negative ideal one is given by

$$
S^{-}=\sqrt{\sum_{j=1}^{n}\left(v_{i j}-v_{j}^{-}\right)^{2}}
$$

where $\mathrm{i}=1,2, \ldots, \mathrm{m}$

Separation Measures calculated are given in Table IX.

Step 6-

Calculate the relative closeness to the ideal solution. The relative closeness of $A_{i}$ with respect to $A$ is defined as:

$$
C_{i}^{*}=S_{i}^{-} /\left(S_{i}^{*}+S_{i}^{-}\right)
$$

$0 \leq \mathrm{Ci}^{*} \leq 1$ where $\mathrm{i}=1,2, \ldots, \mathrm{m}$

The larger the $\mathrm{Ci}^{*}$ value the better the performance of the alternatives.

Step 7- Rank the preference order.

TABLE IX. SEPARATION MEASURES

\begin{tabular}{|l|l|l|}
\hline Alternatives & $S^{*}$ & $S^{-}$ \\
\hline TFR & 0.04 & 0.0409 \\
\hline RF Capacitance & 0.0175 & 0.0485 \\
\hline RADAR & 0.0251 & 0.0417 \\
\hline Ultrasonic/Sonic & 0.0251 & 0.0417 \\
\hline Magnetostrictive & 0.0374 & 0.0337 \\
\hline $\begin{array}{l}\text { Anisotropic Magneto } \\
\text { resistive }\end{array}$ & 0.0407 & 0.0315 \\
\hline Hall Effect & 0.0375 & 0.0379 \\
\hline Reed Switch & 0.038 & 0.0404 \\
\hline LVDT & 0.0258 & 0.0401 \\
\hline
\end{tabular}

\section{RESULTS}

1) Total Score obtained by alternatives by Pugh Matrix Selection are shown in Table X.

TABLE X. SCORES

\begin{tabular}{|l|c|c|}
\hline Alternatives & Scores & Rank \\
\hline RF Capacitance & 36 & 1 \\
\hline RADAR & 31 & 3 \\
\hline Ultrasonic/Sonic & 3 & 6 \\
\hline Magnetostrictive & 3 & 6 \\
\hline Anisotropic Magneto resistive & -3 & 8 \\
\hline Hall Effect & 23 & 4 \\
\hline Reed Switch & 7 & 5 \\
\hline LVDT & 35 & 2 \\
\hline
\end{tabular}

2) Closeness Index for alternatives by TOPSIS method is given in Table XI along with Ranks.

TABLE XI. CLOSENESS INDEX

\begin{tabular}{|l|c|c|}
\hline Alternatives & $\begin{array}{l}\text { Closeness } \\
\text { Index }\end{array}$ & Rank \\
\hline TFR & 0.5052 & 6 \\
\hline RF Capacitance & 0.7349 & 1 \\
\hline RADAR & 0.624 & 2 \\
\hline Ultrasonic/Sonic & 0.624 & 2 \\
\hline Magnetostrictive & 0.4741 & 8 \\
\hline
\end{tabular}


Asia Pacific Journals

\begin{tabular}{|l|c|c|}
\hline $\begin{array}{l}\text { Anisotropic } \\
\text { Magneto } \\
\text { resistive }\end{array}$ & 0.4368 & 9 \\
\hline Hall Effect & 0.5025 & 7 \\
\hline Reed Switch & 0.5154 & 5 \\
\hline LVDT & 0.608 & 4 \\
\hline
\end{tabular}

\section{CONCLUSIONS}

RF Capacitance, LVDT, RADAR, Hall Effect type fuel sensor are high scorers based on Pugh Selection Matrix. With TOPSIS Method, RF Capacitance, RADAR, Ultrasonic/Sonic are top three alternatives. As LVDT level sensors are used for measuring liquid height up to $100 \mathrm{~mm}$; but fuel tank height of Heavy Commercial Vehicles more than $500 \mathrm{~mm}$, so LVDT level sensors cannot be used for this application. So by both decision making methods, RF Capacitance type fuel level sensor comes out to be the most appropriate technology alternative for Fuel level Sensing of Heavy Commercial Vehicles.

\section{Acknowledgement}

Authors are grateful for the help received from $\mathrm{Mr}$. Kumar Ankur, Mr. Unmesh Nagarkar, Mr. Rakesh Burde, Mr. Saurabh Mukadam from TATA Motors Ltd, CVBU, PimpriPune. Authors also thank colleagues from College of Engineering, Pune for their support while writing this paper.

\section{REFERENCES}

[1] URL: http://www.wema.com/?page $=417 \&$ show $=480$.

[2] URL: http://www.fine-tek.com/main/index.aspx?flag=1.

[3] URL: https://en.wikipedia.org/wiki/Level sensor-

[4] URL: http : / / www . infineon . com / dgdl / AppNote Liquid Level- Sensing-Rev . 1 . 0 . pdf ? fileId = db3a30432313ff5e0123a385f3b2262d.

[5] URL: http://sensing.honeywell.com/products/fiberopticsensors? $\mathrm{Ne}=2308 \& \mathrm{~N}=3037$.

[6] Pema Wangchen Bhutia and Ruben Phipon- "Application of AHP and TOPSIS Method for Supplier Selection Problem", IOSR Journal of Engineering, Volume 2, Issue 10, pp. 43-50, 2012

[7] Fleming, W. J. -"New automotive sensors-A review", IEEE Sensors Journal, 2008, vol. 8, no. 11, pp. 1900-1921

[8] Anandaraj N., "Design and Development of Capacitance Type Level Sensor for Automotive Vehicle Application," SAE Technical Paper 2015-26-0015, 2015, doi: 10.4271/2015-26-0015

[9] Burge, D. S. (2011) - "The Systems Engineering Tool Box". Retrieved

fromhttp://www.burgehugheswalsh.co.uk/uploaded/documents/CDTool-Box-V1.0.pdf

[10] John Schnake- "Liquid level measurement", White Paper

[11] Mazzorana, R., da Silva Junior, O., and de Oliveira, R., "Fuel Tank - Level Sensor Technology Selection Based on Engineering Criteria and Application Environment," SAE Technical Paper 2014-36-0128, 2014, doi: 10.4271/2014-36-0128

[12] Smith, E. and Ireland, H., "Design Guidelines for Automotive Fuel Level Sensors," SAE Technical Paper 2002-01-1074, 2002, doi: 10.4271/2002-01-1074.

[13] Level Sensor. n.d. from https://en.wikipedia.org/wiki/Level_sensor

[14] Sandeep Chakravorty ,Smarajit Ghosh, "Power Distribution Planning using Multi $\square$ Criteria Decision Making Method", International Journal of Computer and Electrical Engineering, Vol. 1, No.5, pp.622 $\square 627$, December 2009 . 